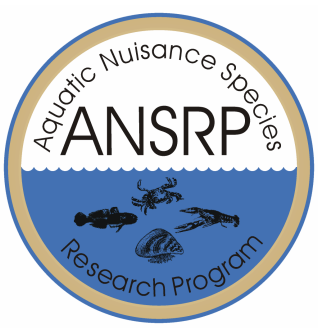

\title{
Application of Risk Assessment and Decision Analysis to Aquatic Nuisance Species
}

\section{by Burton C. Suedel, Todd S. Bridges, Jongbum Kim, Barry S. Payne, and Andrew C. Miller}

PURPOSE: This technical note describes a structured framework for conducting risk assessments for aquatic nuisance species (ANS). The technical note also describes when and how decision analysis tools can be used in such assessments for ANS. This framework and methodology will enable risk managers to systematically evaluate and compare alternatives and actions supporting ANS risk management and thus credibly prioritize resources.

BACKGROUND: Risk assessment is a globally accepted tool for assessing the potential harm posed by chemical contaminants in the environment (Andersen et al. 2004a). Recently, work has begun that combines the benefits of risk assessment with the structure provided by decision analysis to bridge the gap between the detailed, quantitative output of risk assessments and simulation models with values-based and localized risk management requirements (Kiker et al. 2005; Linkov et al. 2005). An approach using the traditional ecological risk assessment (ERA) framework (USEPA 1997, 1998) combined with decision analysis tools has appeal for assessing ANS risks. While the methodology for contaminant risk assessment is well-known and universally applied, the elements of a toxicologically based risk assessment paradigm will need to be adapted to cases where the causative agent for a perceived risk to the environment is an organism rather than a chemical. To effectively manage ANS risks, a systematic risk assessment framework that includes structured decision analysis can help organize and analyze pertinent data, state assumptions, address uncertainties in estimating the probability of an undesired event, and integrate these outputs with stakeholder values.

INTRODUCTION: The establishment and spread of nonindigenous (non-native) species introduced into the United States is a significant and growing national problem. Problems are manifested via lost agricultural productivity, increased health problems, environmental degradation to the point of extinction of native species and expensive prevention and eradication efforts (Andersen et al. 2004a; U.S. Congress, Office of Technology Assessment (USOTA) 1993; Mack et al. 2000). The economic costs due to the introduction of nonindigenous species in the United States are at least \$137 billion per year (Pimentel et al. 2000). Approximately 50,000 nonindigenous species introductions were documented in the United States by the year 2000 (Pimentel et al. 2000) and approximately 4,500 of these species have either become established or spread (USOTA 1993). About 300-400 ANS occur in marine and estuarine environments in North America (Ruiz et al. 1999, 2000). There are 53 species of invasive aquatic weeds in the Hudson River basin alone and roughly $\$ 100$ million is spent each year in the United States to control nuisance aquatic plant species (Pimentel et al. 2000).

Of more immediate concern to the USACE is that ANS pose ongoing and potential future threats to USACE activities. Some ANS pose threats to infrastructure such as navigation or water control structures by burrowing into earthen structures such as levees or attaching to hard structures such as buoys, piers, and water intakes. Other ANS may undermine earthen levees or interfere with habitat 
restoration efforts in wetlands, oyster and seagrass beds, and other coastal habitats as well as interfere with natural recruitment processes on recently placed dredged material (Ray 2005).

ANS risk assessment is a deliberate, analytical methodology of identifying how a target resource could be vulnerable to ANS establishment and estimates the probability that a threat will harm a resource with some predictable severity of consequences (Andersen et al. 2004a). However, risk assessments currently being used (e.g., the U.S. Department of Agriculture (USDA) Animal and Plant Health Inspection Service (APHIS) Guidelines for Pathway-Initiated Pest Risk Assessments (USDA 2000)) rely on qualitative or semi-quantitative information and expert opinion. Such approaches also lack transparency and repeatability. More quantitative approaches are needed to augment the qualitative approaches currently in use (Andersen et al. 2004a).

The authors thus adapted the existing risk assessment framework for chemical contaminants (USEPA 1997, 1998) to the problem of assessing environmental risks posed by ANS. This required recasting the concepts of exposure and effects assessment in terms of biology and ecology rather than chemistry and toxicology. Exposure to a chemical is a process dominated by physics and chemistry, while characterizing "exposure" to nuisance species that have distinct behaviors, that reproduce, prey on, and compete with other species in the system for resources can only be accomplished using an ecologically based analysis structure and complementary tools such as quantitative uncertainty analysis, theoretical ecological models, and multicriteria decision analysis. Risk-informed decision-making that considers both estimates of the probability of harm and the uncertainty associated with those estimates can be accomplished through the structure and discipline provided by risk assessment.

ECOLOGICAL RISK ASSESSMENT: Ecological risk assessment (ERA) evaluates the likelihood that adverse ecological effects may occur or are occurring as a result of exposure to one or more stressors (USEPA 1998). The USEPA ERA paradigm consists of three primary elements (Figure 1): problem formulation, analysis of exposure and effects, and risk characterization (USEPA 1997, 1998). Activities that occur within each element are discussed briefly below.

During problem formulation, assessment endpoints are developed that adequately reflect management goals and the ecosystem they represent, conceptual models are developed that describe key relationships between a stressor(s) and assessment endpoint, and an analysis plan is developed that describes how data will be collected and used to support ERA conclusions (USEPA 1998). Early assessment of available information begins during problem formulation. Problem formulation also evaluates how well available information on stressor sources and characteristics, exposure opportunities, characteristics of the ecosystem(s) potentially at risk, and ecological effects are integrated and used.

The analysis phase of ERA examines the two primary components of risk, exposure and effects, and their relationships between each other and ecosystem characteristics (USEPA 1998). Data are provided for predicting ecological responses to stressors under prevailing exposure conditions. Analysis connects problem formulation with risk characterization. The assessment endpoints and conceptual models developed during problem formulation provide the focus and structure

\section{Definitions}

Risk - the likelihood of harm Exposure - contact of an ANS with a resource Effects - results produced by ANS introduction, establishment or spread 
for the analysis phase. Analysis phase products are summary profiles that describe exposure and the relationship between the stressor(s) and responses in receptors. These profiles provide the basis for estimating and describing risks in risk characterization.

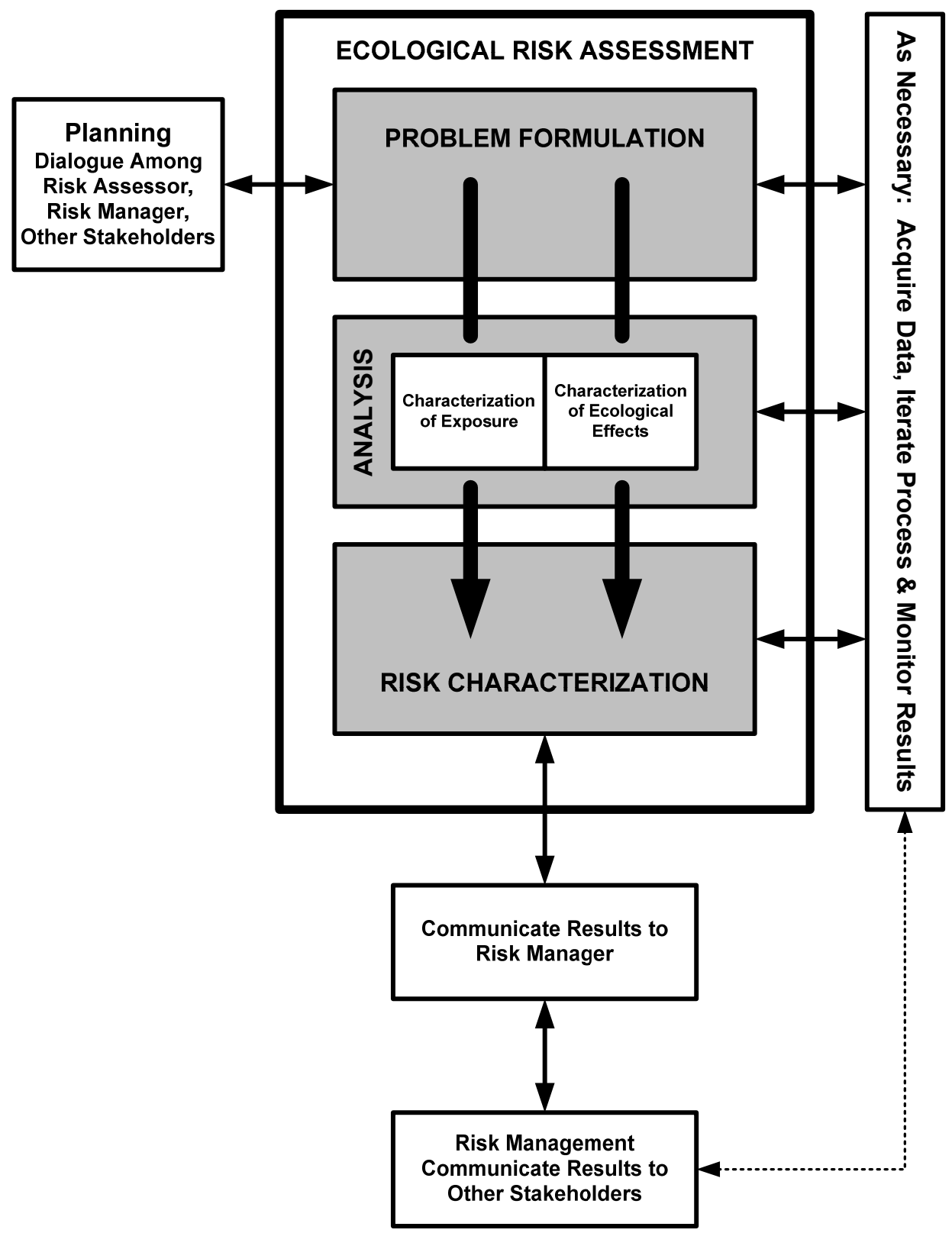

Figure 1. Traditional ecological risk assessment framework developed by USEPA.

Risk characterization follows problem formulation and analysis and predicts adverse ecological effects related to the assessment endpoints (USEPA 1998). Risk characterization clarifies the relationships between stressors, effects, and ecological receptors and reaches conclusions regarding the occurrence of exposure and the presence of existing or potential effects. Risk estimates are described and all lines of evidence are presented. Risk characterization also identifies and summarizes the 
uncertainties, assumptions, and qualifiers in the risk assessment and reports the conclusions to risk managers.

Comparison of Traditional ERA with ANS Risk Assessment. Risk assessment of ANS as proposed herein is similar to the traditional ERA framework in several ways. These include:

- A flexible framework consisting of three main elements: problem formulation, analysis, and risk characterization.

- The importance of communicating results to decision makers and stakeholders in a manner that is clear and transparent.

- An iterative process that works to focus an assessment through the collection and use of relevant data.

- A framework in which risk of a variety of chemical, biological, and physical stressors can be assessed.

Several aspects of ANS risk assessment differ from traditional ERAs where chemicals are the primary stressors.

- Stressor exposure in ANS ERA involves a progression of processes and likelihoods, includeing those related to species introduction, establishment, and spread. Exposure also includes processes related to the interaction between the introduced species and native communities and ecosystems. Successful establishment and spread depends on a number of factors, including the lack of controlling natural enemies, the ability of a nuisance parasite to switch hosts, an ability to be an effective predator in a new ecosystem, the availability of disturbed habitats that provide a highly invadable ecosystem for ANS, and high adaptability to novel conditions (Pimentel et al. 2000).

- Effects assessment in traditional ERA becomes "consequences of establishment" in ANS. Here the potential environmental, economic, social/political and public health effects are ascertained (National Science and Technology Council (NSTC) 1999).

- In traditional ERAs, risk assessment is deliberately separated from risk management so that the data generated during risk assessment are kept separate from value judgments inherent in the risk management process. In a departure from traditional ERA, risk management is incorporated into the ANS framework because of the need to acquire input from decision makers and stakeholders during risk characterization. ANS risk assessment and risk management are integrated so that the necessary connections are made between the social values at stake in ANS decisions and the data (science) generated to predict the impacts of management actions (Maguire 2004). Integrating risk assessment and management in this manner permits the use of decision analysis to incorporate both science and societal values into the decisionmaking process.

- Unlike ERA where chemical concentrations in environmental media are relatively constant over time (especially organic compounds), the size of an ANS population will change over time (e.g, increase and potentially spread) as it adapts to a new environment (NSTC 1999).

- In traditional ERAs, the mechanisms by which chemicals can impact biota are relatively well understood. Conversely, in ANS risk assessment, there is a broad range of mechanisms by which ANS can directly or indirectly impact target resources. Mechanisms can include 
predation, grazing, parasitism, infection, hybridization, direct and indirect competition, physical habitat alteration, changes in predator-prey interactions and alterations to hydrology, nutrient cycles and energy flows (Andersen et al. 2004a, Landis 2004).

- Communication with decision-makers and stakeholders can occur at any time during the risk assessment process rather than only during problem formulation and risk management. The ability to communicate at any time during the ANS risk assessment process allows for promptly addressing issues that may arise.

- Unlike traditional ERA where chemical stressors can be remediated in a relatively short period of time (e.g., months), the management strategies for ANS are likely to be implemented over several years or decades.

THE ANS RISK ASSESSMENT FRAMEWORK: The ANS risk assessment framework has three components: problem formulation, analysis, and risk characterization (Figure 2). Risk assessment for ANS can be conducted in cases where risks to plants, animals, and other wildlife are ongoing and the potential expansion of these impacts is the question under investigation. It can also be used to assess the probability of ANS establishment.

The ANS framework offers the flexibility to perform the level of effort required to meet project goals and objectives. In some cases a less time-consuming assessment may be appropriate where semi-quantitative tools are used to assess ANS risk. This type of assessment may serve as a semiquantitative screening assessment, where risks are estimated using current data and default assumptions regarding the biology and ecology of ANS and target resources. In other cases where objectives require a more quantitative analysis, and time and budget allow, more complex ecological models may be appropriate. In such cases, time and resources will be expended to collect the data required as input to such models.

The bar along the right side of Figure 2 highlights data acquisition, iteration, and monitoring. Monitoring data provide important input to all phases of a risk assessment. They can provide the impetus for a risk assessment by identifying changes in ecological condition. The bar on the left side highlights the communication between risk assessors, decision-makers, and stakeholders. Communication among these groups should begin early in problem formulation and continue throughout the duration of the ANS risk assessment process, as needed. A more detailed description of each element of the ANS risk assessment framework is provided below.

Problem Formulation. Problem formulation provides a means of defining the problem in writing, including known or suspected causes of the problem related to ANS (Figure 3). Developing a common statement of the problem that is understood and accepted by risk assessors, decision-makers, and interested parties (i.e., stakeholders) ensures that subsequent project activities and decisions will address ANS concerns. A clearly articulated problem statement will allow the project team to establish a comprehensive set of goals and objectives. Once the list of specific goals and objectives is assembled, project-specific decision criteria should be developed that will be used to rank alternative actions in terms of their ability to meet project objectives. The decision criteria will also be used as a guide for generating the data needed to meet project goals. 


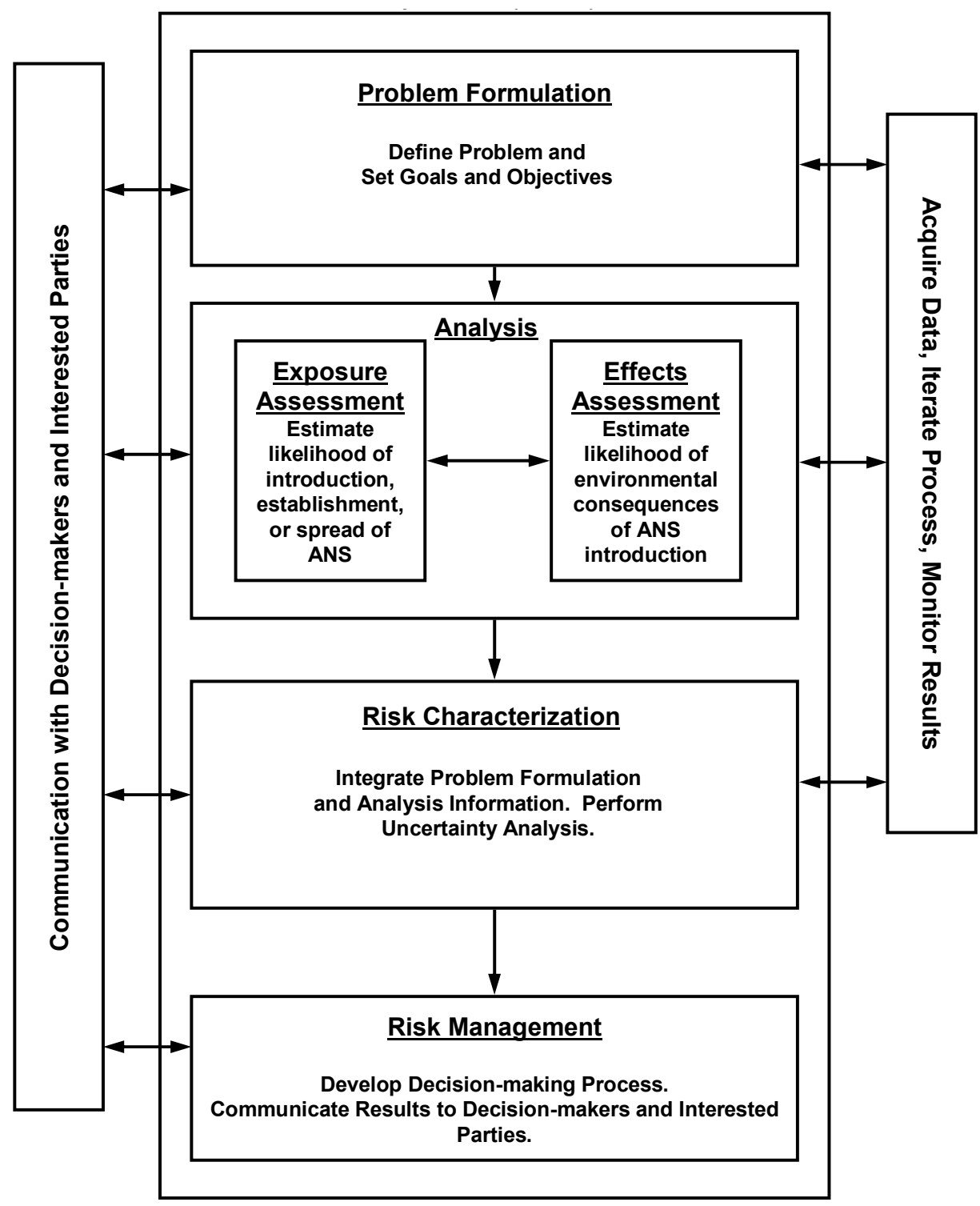

Figure 2. Risk and decision framework for aquatic nuisance species (ANS).

Problem formulation also compiles existing data or generates new data to satisfy the needs of all interested parties. Data needs will likely include information on the biology, ecology and life history of ANS, environmental factors influencing ANS establishment (e.g., temperature), population dynamics of ANS, identity of pathways (e.g., location and volume) of entry or spread, susceptible resource characteristics, potential biological consequences of spread, and identity of goods and services provided by the target resources along with their economic value. Problem formulation also evaluates the completeness and usability of available data on ANS sources and characteristics, exposure opportunities, characteristics of the ecosystem(s) potentially at risk, and ecological effects. Integration of available information begins within problem formulation and is iterative throughout the ANS risk assessment process. 


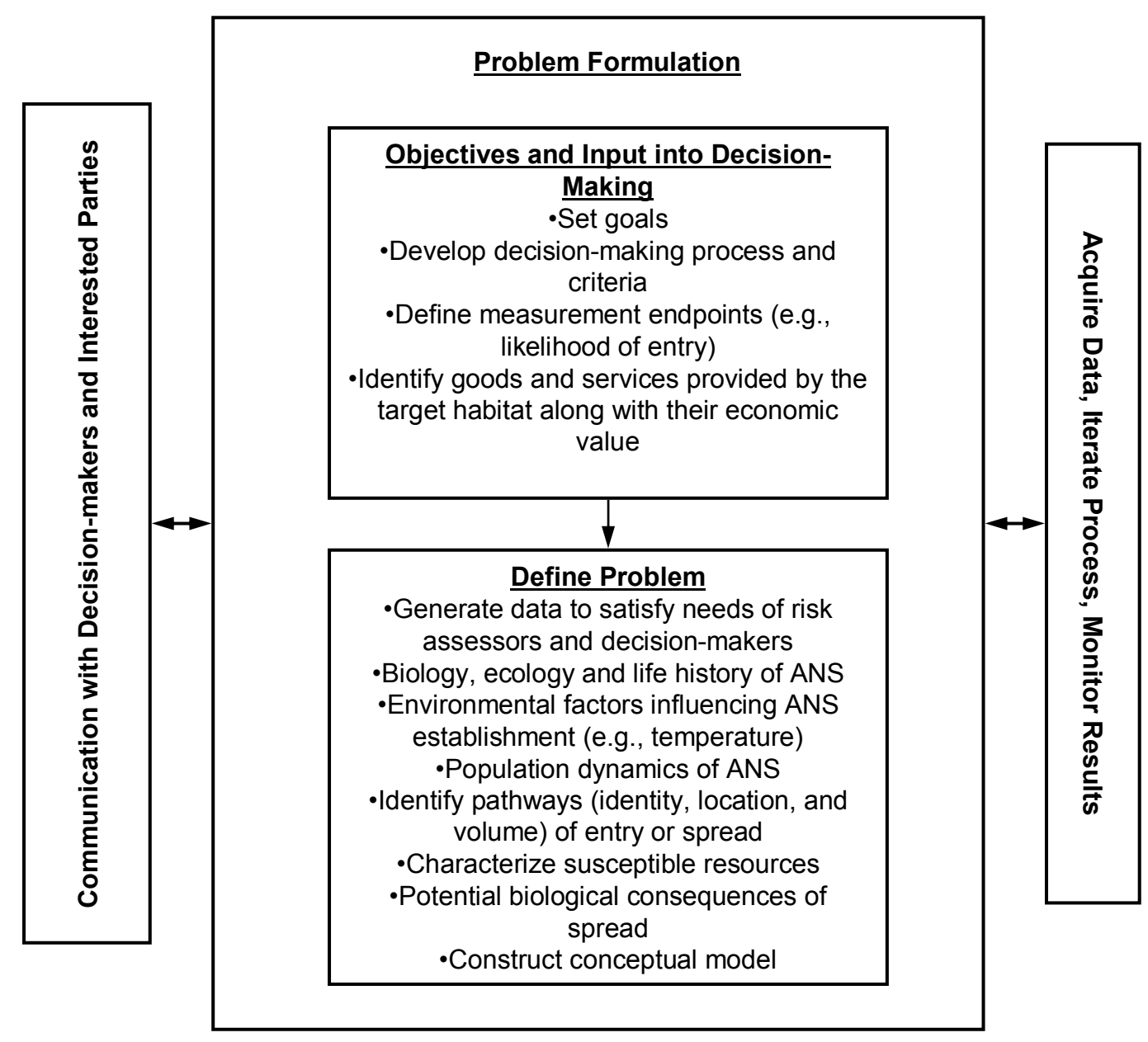

Figure 3. Problem formulation phase of ANS risk assessment.

During problem formulation, assessment endpoints are developed that reflect management goals and the ecosystem they represent and conceptual models are developed that describe key relationships between a stressor(s) and assessment endpoint. Assessment endpoints in ANS risk assessment are the resources that may be affected by an ANS introduction or spread (Andersen et al. 2004b). Table 1 provides some example objectives and assessment endpoints for ANS risk assessment relevant to USACE activities.

\section{Table 1 \\ Example objectives and assessment endpoints for ANS}

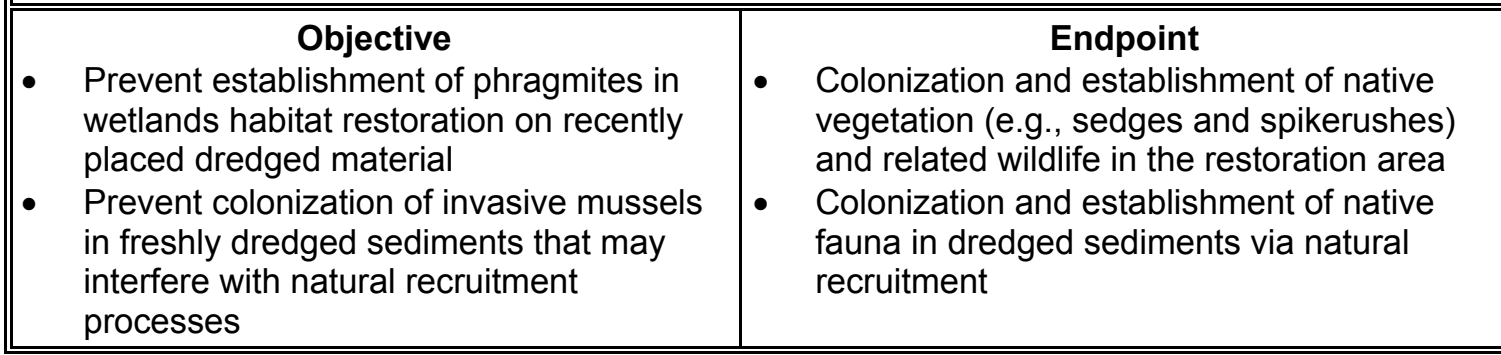


Problem formulation focuses project activities on the decisions that are required to achieve project objectives. This focus on decision-making establishes the context for data collection, analysis, and model development activities. By developing an explicit, written set of project objectives and decision criteria early in the risk assessment process, the data needed for decision-making can be established. Problem formulation also provides a means in which risk assessors, decision-makers, and stakeholders can build a structure to effectively communicate and collaborate. The ANS framework allows this communication to continue throughout the entire risk assessment process (Figure 2).

Conceptual Model Development. Problem formulation in traditional ERA culminates with a conceptual model that identifies the sources, complete or potentially complete exposure pathways, contaminated media, transport mechanisms, and receptors at risk (USEPA 1997). For ANS risk assessment, the conceptual model serves a similar role. Sources are locations (e.g., ballast water and hulls of ships) that release ANS. Complete or potentially complete exposure pathways are the ways that ANS can be transported from the source to receptor habitats (e.g., wind, currents, etc.). Once exposed, target resources interact with ANS. The nature of such exposure interactions between ANS and resident fauna can be direct or indirect and can take many forms (Table 2). For example, ecological interactions can occur through direct competition over food resources or indirectly by altering habitat.

\begin{tabular}{|c|c|}
\hline \multicolumn{2}{|c|}{$\begin{array}{l}\text { Table } 2 \\
\text { Examples of direct and indirect effects of ANS on target resources }\end{array}$} \\
\hline \begin{tabular}{cl} 
Ecological & \multicolumn{1}{c}{ Direct Effects } \\
- & Predation \\
- & Grazing \\
- & Parasitism \\
- & Infection \\
- & Hybridization \\
- & Extinction \\
Human Health \\
- Disease vectors \\
- Allergens \\
Economic \\
- Impede navigation \\
- Foul water control structures \\
- Enhance flooding \\
- Reduction in fisheries survival, \\
Impair drinking water supply
\end{tabular} & $\begin{array}{l}\text { Ecological } \\
\text { Can Alter: } \\
\text { - Habitat } \\
\text { - } \text { Fire regimes } \\
\text { - Hydrology } \\
\text { - Nutrient cycles } \\
\text { - } \quad \text { Predatorects flows } \\
\text { Human Health } \\
\text { - Aesthetics } \\
\text { - Sheltered habitat for mosquitoes, which } \\
\text { Economic } \\
\text { - Could serve as disease vectors } \\
\text { - } \quad \text { control, of combating invasions: quarantine, } \\
\text { - Reduced recreational use }\end{array}$ \\
\hline
\end{tabular}

Receptors at risk are the target resources including habitats and associated wildlife that are of concern (e.g., intertidal mudflat) and where ANS may migrate. Stressors other than ANS (biological, chemical, physical) may also influence whether ANS establish or colonize an area (Ruiz et al. 1999, Landis et al. 2004) and should be considered when developing the conceptual model. Some 
anthropogenic stressors (e.g., climate change, fishing fleets, alteration of habitats, eradication efforts) can be used to eliminate sources, sever migration pathways, or alter target resources to prevent or slow the establishment of ANS (Landis 2004).

Conceptual models in ERA serve as a tool to organize subsequent data collection and analysis activities within the risk assessment itself. Likewise, conceptual models in ANS risk assessment will be relied upon to an even greater extent to communicate understanding of how ANS are posing risks to target resources at the conclusion of the risk assessment. This can be accomplished by describing exposure pathways, the resources at risk and the trade-offs of implementing different engineering or remedy options so that informed decisions can be made.

Analysis. Like traditional ERA, the analysis phase of ANS risk assessment consists of an assessment of exposure and an assessment of effects (Figure 4). For ANS, exposure assessment involves estimating the likelihood of introduction, establishment, and spread of an ANS. Exposure assessment may also consider the quantity, timing, frequency, duration, and routes of exposure and the numbers, species, and susceptibility of the target resources (Andersen et al. 2004a). Effects assessment in the ANS framework involves estimating the likelihood and severity of environmental, socio-economic, and public health consequences of ANS exposure to target resources (NSTC 1999; Andersen et al. 2004a). Effects assessment considers both direct and indirect effects of ANS on target resources (Table 2).

Two approaches, representing differing levels of effort and complexity, can be used in the analysis phase of ANS risk assessment: semi-quantitative and quantitative. The semi-quantitative approach uses existing data, semi-quantitative tools, and professional judgment to assess ANS risk. For example, tools can include environmental matching (degree in which the new environment is similar to environment where ANS is native), propagule pressure (the number of ANS individuals released), species traits (e.g., previous invasion history elsewhere), and expert opinion (comprehensive assessment of current biological and ecological data to confirm results from other tools) (Daehler and Strong 1993). This type of analysis approach can be performed relatively rapidly, but the uncertainties associated with such an approach may limit the utility of the resulting decision-making predictions.

Models based on theoretical ecology can be used to assess the exposure or effects of an ANS with varying degrees of complexity. Models that can potentially be used include individual-based, demographic, diffusive transport, neutral landscape and spread models and gap, pathway, and population viability analysis (Andersen et al. 2004b, Bartell and Nair 2004, With 2004). Such models have been used to predict the extinction of threatened and endangered species, while others such as the diffusive transport model have been used to predict the spread of nonindigenous species (Andersen et al. 2004b, Bartell and Nair 2004). Some models have been developed to predict invasion speed of nonindigenous species (e.g., Neubert and Caswell 2000; Neubert et al. 2000). While such models can be used in the ANS framework, it should be noted that few models have been developed to predict the introduction of ANS so these models would have to be adapted to fit the ANS risk assessment framework. The choice of model should ultimately depend on the goals and objectives of the risk assessment and available data. 


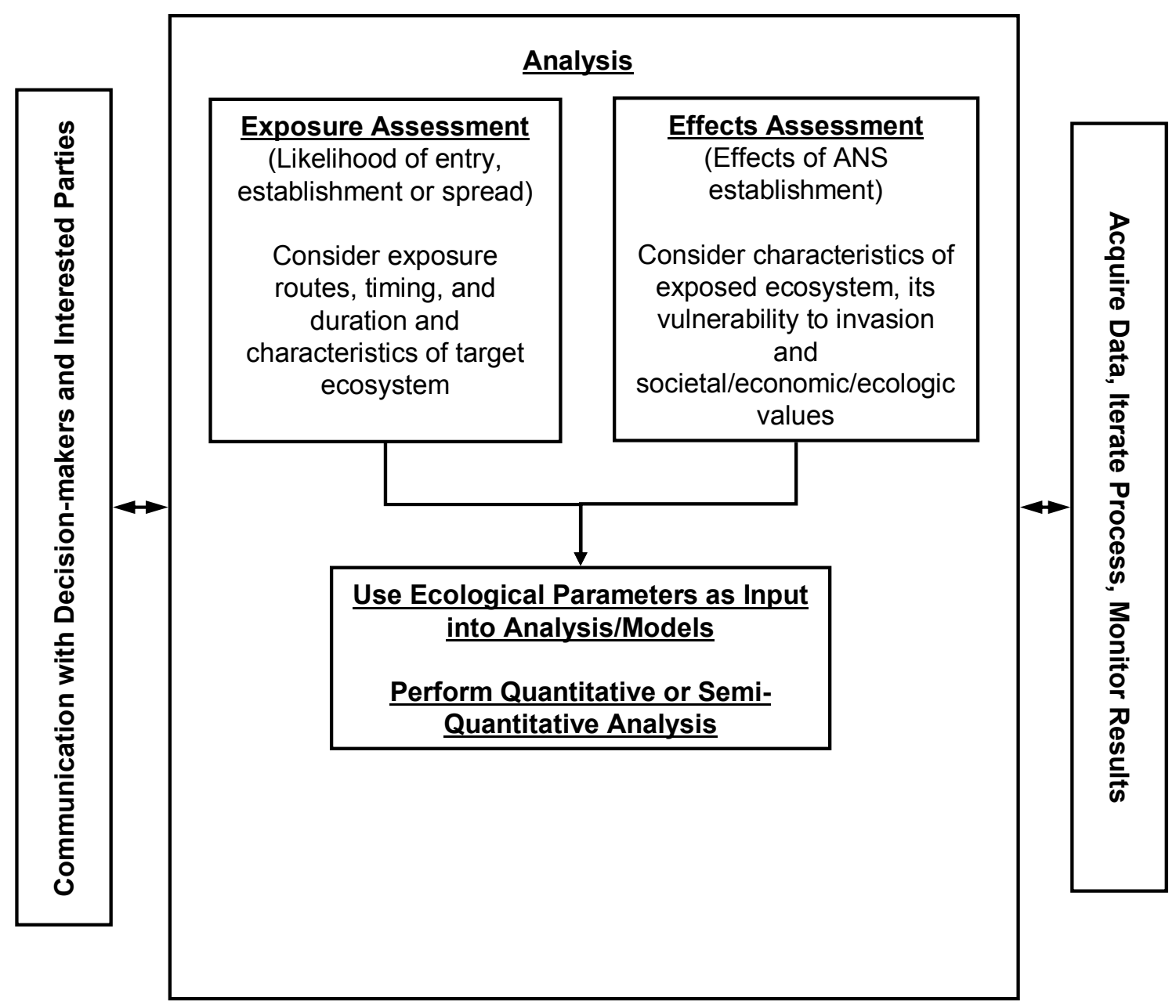

Figure 4. Analysis phase of ANS risk assessment.

Advancing the science and management of ANS, an environmental problem that is increasing in scope within the United States, depends on making progress toward developing such quantitative approaches. The potential environmental and economic harm posed by ANS and the costs of implementing ANS management strategies warrants a greater investment in developing quantitative approaches that lend themselves to detailed uncertainty analysis.

Risk characterization. Risk characterization, similar to evaluating chemical stressors in ERA, integrates problem formulation and analysis information, including exposure and/or effects components, to synthesize an overall conclusion about ANS risk that can be clearly articulated to decisionmakers and stakeholders (Figure 5) (Andersen et al. 2004a). Risk characterization culminates the problem formulation and analysis of predicted or observed adverse ecological effects related to the assessment endpoints (USEPA 1998). Risk characterization clarifies the relationships between ANS and target resources and reaches conclusions regarding the presence of existing or potential effects. Risk estimates are provided and results from all assessment tools are summarized. Risk characterization also identifies and summarizes the uncertainties, assumptions, and qualifiers in the risk assessment and reports the conclusions in a manner that is clear, understandable, and transparent to decision-makers and stakeholders. Characterization of ANS risk includes a section on the 
uncertainty of the analysis, and communication of results to risk managers via decision analysis, as described below.

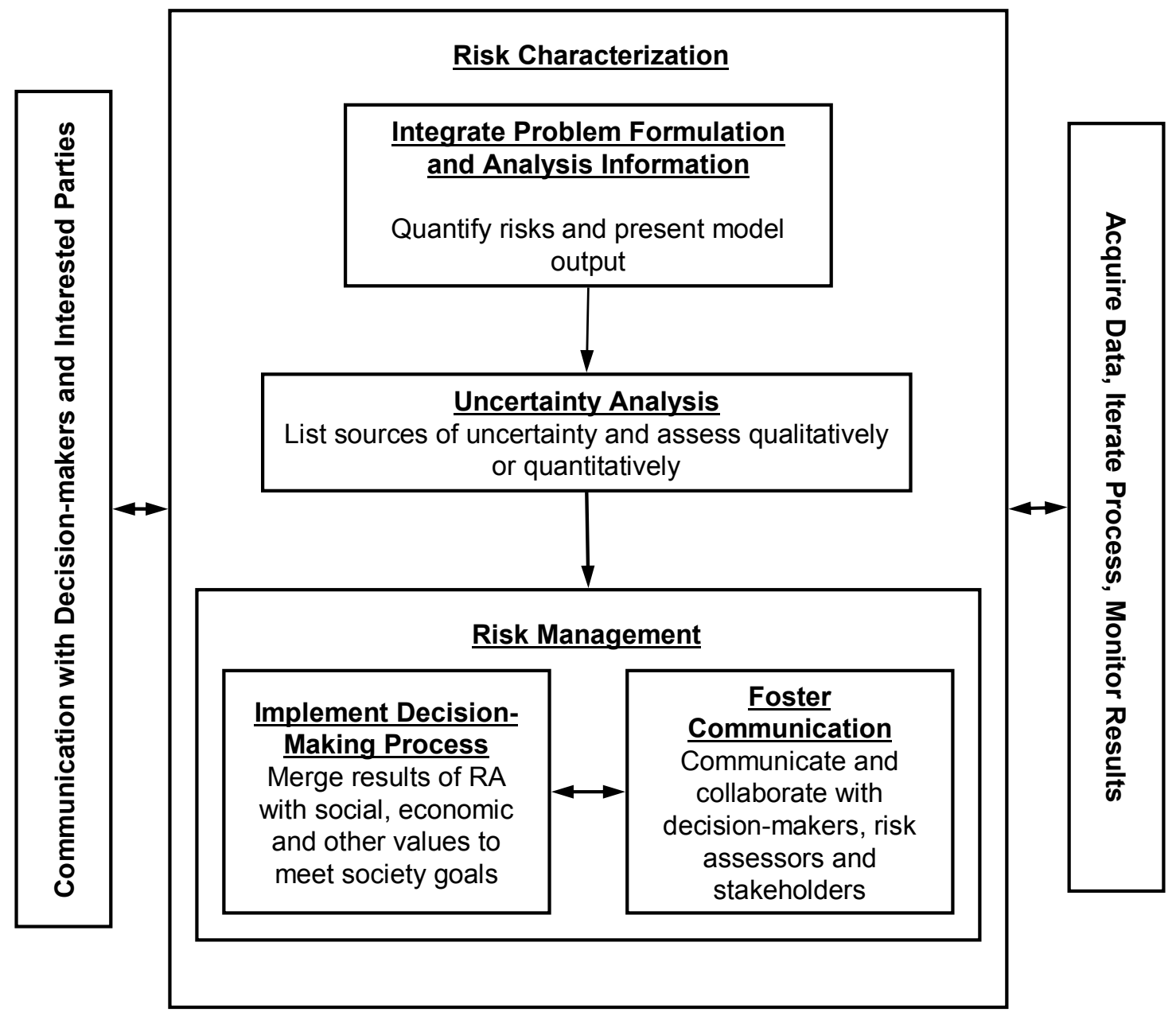

Figure 5. Risk characterization phase of ANS risk assessment.

Uncertainty Analysis. It is important that limitations associated with ANS risk assessment and their associated analyses and application be presented as part of risk characterization. Limitations associated with ERAs include the degree of success in meeting objectives, the range of conditions over which conclusions can be applied, and the certainty with which conclusions can be drawn (USEPA 1989). The results of any risk assessment are useful only after they have been placed in perspective relative to the uncertainties associated with conducting the ERA.

Uncertainty in risk estimation has both qualitative and quantitative components. Uncertainty of risk estimates includes lack of knowledge, both inherent biological variation (reflecting actual, mechanistic biological response ranges and variability in ecosystem conditions) and measurement error (USEPA 1998). For accurate estimation of site-specific risks, ecosystem variability must be accounted for as accurately as possible and measurement error should be minimized. The consequences of making errors in ANS risk assessment may be substantial. For example, the harm to environmental resources resulting from mistakenly accepting a low risk estimate for an invasive species is 
likely to be greater than when a species ultimately found not to be invasive is mistakenly rejected (Maguire 2004). The perception of how much greater will depend on the stakeholders and decisionmakers participating in the process (e.g., importers versus the USACE districts).

Risk Management. In traditional ERA, risk assessment is deliberately separated from risk management (Figure 1) so that data (science) generated during risk assessment is kept separate and not compromised by value-laden judgments and preferences inherent in the risk management process (USEPA 1998, Maguire 2004). However, in an obvious departure from traditional ERA, risk management is within the ANS framework because of the need to acquire input from decision-makers and stakeholders during risk characterization (Figure 5). This need to gather input from interested parties necessitates the implementation of a decision-making process during risk characterization. This process may use decision-making tools such as Multi-Criteria Decision Analysis (MCDA), which offers a broad framework for solving complex problems such as those encountered in ANS risk assessment (Maguire 2004).

In ANS risk management, the results of the risk assessment are integrated with other considerations to make and justify risk management decisions. In general terms, risk assessment will be used to make decisions about ANS entry and control. Entry decisions consider whether to restrict routes of entry for potential ANS that may be introduced either inadvertently or purposefully through horticulture or aquarium trade, for example. Decisions about control occur after an ANS has established or spread, and primary concerns are resource allocation, setting priorities for control, and deciding which control methods to use. The effectiveness of each of the numerous potential decisions that will need to be made by decision-makers and stakeholders during risk management can be evaluated prior to implementation via a decision analysis process (Maguire 2004). As discussed below, decision analysis allows for input of both the scientific data and society values in the decision-making process.

ANS management actions will have a direct impact on the environment, economy, and society. Controversy arises in ANS management because (1) people have different objectives with different priorities, and (2) people expect different outcomes from management decisions. While risk characterization represents the likelihood of various outcomes, it does not inform whether outcomes of alternative management actions are desirable or acceptable. In addition, the ecosystem in which natural resource managers operate is subject to inherent uncertainty associated with management actions. An important question in ANS management is how to balance the many objectives and resolve conflicts that may result from a lack of consensus on the desired state of the ecosystem as well as uncertainties about facts. Decision analysis can provide such conflict resolution (Kiker et al. 2005).

Decision Analysis. Decision analysis is a tool for considering both uncertainties and the multiple dimensions of value; it can contribute to better decisions by helping managers to structure the problem, balance risks, and compare options based on outcomes and expressed preferences (Keeney and Raiffa 1976, Clemen 1995). For example, risk assessors may propose several distinct hypotheses concerning ANS impacts, and their implications for management actions. Such scientific debate adds to the already considerable uncertainty faced by decision-makers resulting from, e.g., error-laden estimates of population sizes and weather-dependent recruitment rates. Despite these uncertainties, decision-makers must make decisions about, for example, control and entry. A useful device for 
structuring problems is the decision tree, which contains decision nodes, uncertainty nodes, and outcomes (Kim and Bridges 2005). A tree is used to show the performance of given decision alternatives under alternative scenarios and to facilitate the calculation of optimal strategies.

With the help of decision trees and other tools, decision analyses can yield various indices that aid ANS decision-makers (Kim and Bridges 2005, Payne and Miller 2004). These indices include quantification and analysis of tradeoffs among objectives, quantification of value, propagation of uncertainty, and consideration of attitudes towards risk. Such tools have yielded helpful insights in environmental management contexts where many interests are represented and potentially conflicting objectives and uncertainties exist (e.g., Gregory and Keeney 1994, McDaniels 1995). To date there have been few published applications of the use of formal decision analysis in ANS management issues, despite increasing indications that it could play a useful role. For example, the National Research Council (NRC) (2004) emphasized that confronting uncertainty in outcomes and considering multiple objectives can be central to the development of solutions to ecosystem management.

Another function of decision analysis addresses the value of information. The basic approach to assessing the value of information is to compare performance based on decisions that are made without information to performance based on decisions made with better information. The improvement in the expected performance is defined as the value of information. One of the most significant challenges faced by decision-makers is deciding which of several possible data collection or monitoring studies to execute to update knowledge about the environment they are charged with managing. The value of information analysis can quantify how those additional studies could shed light on the credibility of present alternative hypotheses regarding ANS impacts on target resources. Budgets are constrained and the number of possible studies that could be executed is nearly infinite. The chosen project(s) should represent the best possible balance between cost and the value of reduced uncertainty in understanding the ecosystem and formulating decisions to manage that ecosystem.

STRENGTHS AND LIMITATIONS OF APPROACH: The primary strength of using risk assessment is that it provides a framework that takes empirical and modeling data and presents them in a manner that can be used and understood by both decision-makers and stakeholders. This will allow for more effective management of ANS risks (NSTC 1999). This approach will also foster communication among risk assessors, risk managers, and stakeholders and help focus such ANS risk assessments.

Predicting the probability of an ANS invasion in a new environment or the consequences of such an invasion is initially going to be difficult and contain uncertainty, given the lack of 1) models developed for this purpose, and 2) empirical data for many ANS. But carefully planned and executed ANS risk assessments using existing tools can serve as useful input for decision makers managing ANS risks. Once empirical data are obtained for ANS species and knowledge improves regarding the development and use of theoretical ecological models, the proposed ANS risk assessment framework will become an even more valuable tool.

Some say ANS risk assessments cannot been done because insufficient data exist to conduct them, i.e., the uncertainties are too high. This is the very reason why a risk assessment approach should be used to address ANS risks. Risk assessment, more than many other approaches to environmental problem-solving, emphasizes the importance of uncertainty and includes guidance on its assessment and management. Uncertainty is likely to be a dominating issue in ANS decision-making, so the 
approach developed to address ANS risk should include robust tools for characterizing and managing uncertainty.

RISK MANAGEMENT IMPLICATIONS: Determining risk is a central part of the ANS management framework. Management objectives will differ depending on the primary objective: risk of introduction or consequences of introduction.

Risk management goals preventing ANS introduction involve prohibiting an ANS from being introduced into a new environment. As an example, how might the USACE determine which species have the potential to clog intake structures? This can be accomplished by developing screening methodologies such that a species' invasiveness potential is ascertained and deemed acceptably low. As stated previously, the current approaches for screening nonindigenous species are qualitative and involve expert opinion, which produces results that are not repeatable, transparent, quantitative, and do not specify uncertainties. The proposed ANS risk assessment framework will emphasize quantification of risk and uncertainties. It will provide a systematic approach to ANS risk issues to efficiently identify ways of improving the assessment and reducing uncertainties and will provide decision-makers with an enhanced approach for determining the invasiveness of ANS.

Once an ANS has been established, the risk management objective is to slow the spread of the ANS. For example, zebra mussels can attach to barges which can serve as vectors of spread for this ANS; how might the USACE prevent the spread of zebra mussels via barges? This can be accomplished in a number of ways, but the management tools available for control of ANS (biological, chemical, and mechanical) all have inherent strengths and weaknesses (Mack et al. 2000). Mechanical controls can be used to control plants and often have public support, but ANS plants that reproduce vegetatively may spread and the sheer magnitude of spread may render this option impossible due to cost and logistical constraints. Chemical controls are the primary tool for controlling many ANS, but too often they have created health hazards for humans and indigenous species. Biological controls (planned invasions) have been used with success with relatively little cost, but in spite of rigorous host-specific testing, have been known to affect non-target indigenous species. Logistic and economic issues associated with treating barges for mussels would also have to be considered. Decision-makers have to choose between such tools, but they need a structured risk assessment framework to guide their choices and allocate often scarce management resources (Neubert and Parker 2004).

PATH FORWARD: Because the discipline of ANS risk assessment is in its infancy, there are a number of research needs that could improve the ability to predict ANS risk. The greatest needs involve generating empirical data, adapting theoretical models, and adding rigor to current ANS risk approaches. The following actions are suggested:

- Develop a risk-based framework for assessing and managing ANS risk as outlined herein.

- Adapt and develop ecological models for use as tools to assess the risk posed by ANS and the effectiveness of potential management actions.

- Biology, ecology, and effects data for many ANS are lacking. For example, of the 196 nuisance species identified in the Chesapeake Bay, the quantitative data needed to discern impacts are available for only 6 percent of those species (Ruiz et al. 1999). Similarly, in San Francisco Bay the negative effects of only 5 percent of the 230 known nuisance species have 
been quantified (Ruiz et al. 1999). Such data should be generated for species most likely to adversely affect USACE activities (e.g., see list in Ray (2005)).

- Add rigor to (improve) current semi-quantitative approaches. This can be accomplished by developing and adapting ecological models to fit ANS, by developing means of quantifying uncertainty and by using decision analysis to aid ANS decision-making. Current approaches are not quantitative and rely on expert judgment.

- Data describing the interactions between ANS and other anthropogenic stressors are lacking. For example, few data are available that assess the impacts of chemicals, eutrophication, thermal dischargers from power plants or hypoxia on ANS (Ruiz et al. 1999). These data should be generated for species most affecting USACE activities.

- Increase the role of conceptual models in decision-making. Conceptual models in ANS risk assessment will be relied upon to graphically communicate how ANS are posing risks to target resources. These models need to be developed to graphically show exposure pathways, the resources at risk, and the trade-offs of implementing different engineering or remedy options so that informed decisions can be made.

CONCLUSIONS: This technical note describes a structured framework and guidance methodology for conducting ANS risk assessments. When and how decision analysis tools can be used in such assessments is also described. Risk assessment of ANS is similar to traditional ERA in that each provides a flexible framework consisting of three main elements: problem formulation, analysis, and risk characterization. ANS risk assessment differs from traditional ERAs in that stressor exposure in ERA becomes the likelihood or probability of a successful ANS establishment and effects assessment becomes the consequences of establishment. In traditional ERAs, risk assessment is deliberately separated from risk management but it is within the ANS framework because of the need to acquire input from decision-makers and stakeholders during risk characterization. The primary strength of ANS risk assessment is that it provides a framework that takes empirical and modeling data and presents them in a manner that can be used and understood by both decisionmakers and stakeholders. Predicting the probability of an ANS invasion in a new environment or the consequences of such an invasion is initially going to be challenging due to the lack of models and empirical data for ANS. However, the framework and methodology described in this technical note will enable risk managers to credibly distinguish and prioritize resources and to systematically evaluate and compare alternatives supporting ANS risk management.

POINTS OF CONTACT: For additional information contact Dr. Burton C. Suedel, (601) 6344578,Burton.Suedel@erdc.usace.army.mil, or the manager of the Aquatic Nuisance Species Research Program, Mr. Glenn Rhett, (601) 634-3717, Glenn.G.Rhett@erdc.usace.army.mil.

This technical note should be cited as follows:

Suedel, B. C., J. B. Kim, T. Bridges, B. Payne, and A. Miller. 2005. Application of risk assessment and decision analysis to aquatic nuisance species. ANSRP Technical Notes Collection (ERDC TNANSRP-06-4). Vicksburg, MS: U.S. Army Engineer Research and Development Center. 


\section{REFERENCES}

Andersen, M. C., H. Adams, B. Hope, and M. Powell. 2004a. Risk assessment for invasive species. Risk Analysis 24, 787-793.

Andersen, M. C., H. Adams, B. Hope, and M. Powell. 2004b. Risk analysis for invasive species: General framework and research needs. Risk Analysis 24, 893-900.

Bartell, S. M., and S. K. Nair. 2004. Establishment risks for invasive species. Risk Analysis 24, 833-845.

Clemen, R. T. 1995. Making hard decisions: An introduction to decision analysis. Belmont, OR: Wadsworth Pub. Co.

Daehler, C. C., and D. R. Strong, Jr. 1993. Prediction and biological invasions. Trends in Ecology and Evolution 8(10), 380.

Gregory, R., and R. L. Keeney. 1994. Creating policy alternatives using stakeholder values. Management Science 40, $1035-1048$.

Keeney, R. L., and H. Raiffa. 1976. Decisions with multiple objectives: Preferences and value tradeoffs. New York: Wiley.

Kiker, G. A., T. S. Bridges, A. Varghese, T. P. Seager, and I. Linkov. 2005. Application of multicriteria decision analysis in environmental decision making. Integrated Environmental Assessment and Management 1(2), 95-108.

Kim, J. B., and T. S. Bridges. 2005. Risk, uncertainty, and decision analysis applied to the management of aquatic nuisance species, ANSRP Technical Notes Collection (ERDC/TN ANSRP-06-1). Vicksburg, MS: U.S. Army Engineer Research and Development Center.

Landis, W. G. 2004. Ecological risk assessment conceptual model formulation for nonindigenous species. Risk Analysis $24,847-858$.

Linkov, I., S. Varghese, T. P. Jamil, G. Seager, G. Kiker, and T. S. Bridges. 2005. Multi-criteria decision analysis: A framework for structuring remedial decisions at contaminated sites. In Comparative risk assessment and environmental decision-making, ed. I. Linkov and A. Bakr Ramadan, 15-54. The Netherlands: Kluwer Academic Press.

Mack, R. N., D. Simberloff, W. M. Lonsdale, H. Evans, M. Clout, and F. Bazzaz. 2000. Biotic invasions: Causes, epidemiology, global consequences and control. Issues in Ecology 5.

Maguire, L. A. 2004. What can decision analysis do for invasive species management? Risk Analysis 24, 859-868.

McDaniels, T. L. 1995. Using judgment in resource-management - A multiple-objective analysis of a fisheries management decision. Operations Research 43, 415-426.

National Research Council (NRC). 2004. Nonnative oysters in the Chesapeake Bay. Washington, DC: National Academies Press.

National Science and Technology Council (NSTC). 1999. Ecological risk assessment in the federal government. NSTC Committee on Environment and Natural Resources Report No. CENR/5-99/001. May.

Neubert, M. G., and H. Caswell. 2000. Demography and dispersal: Calculation and sensitivity analysis of invasion speed for structured populations. Ecology 81, 1613-1628.

Neubert, M. G., and I. M. Parker. 2004. Projecting rates of spread for invasive species. Risk Analysis 24, 817-831.

Neubert, M. G., M. Kot, and M. A. Lewis. 2000. Invasion speeds in fluctuating environments. In Proceedings of the Royal Society of London B, 267, 1603-1610. 
Payne, B. S., and A. C. Miller. 2004. A probability tree applied to a common zebra mussel dispersal issue. ANSRP Technical Notes Collection (ERDC/TN ANSRP-04-1). Vicksburg, MS: U.S. Army Engineer Research and Development Center.

Pimentel, D., L. Lach, R. Zuniga, and D. Morrison. 2000. Environmental and economic costs of nonindigenous species in the United States. Biological Science 50, 53-65.

Ray, G. L. 2005. Invasive animal species in marine and estuarine environments: Biology and ecology. Aquatic Nuisance Species Research Program Technical Report ERDC/EL TR-05-2. Vicksburg, MS: U.S. Army Engineer Research and Development Center. http://el.erdc.usace.army.mil/elpubs/pdf/trel05-2.pdf

Ruiz, G. M., P. Fofonoff, A. H. Hines, and E. D. Grosholz. 1999. Non-indigenous species as stressors in estuarine and marine communities: Assessing invasion impacts and interactions. Limnology and Oceanography 44, 950-972.

Ruiz, G. M., P. W. Fofonoff, J. T. Carlton, M. J. Wonham, and A. H. Hines. 2000. Invasion of coastal marine communities in North America: Apparent patterns, processes, and biases. Annual Review of Ecology and Systematics 31, 481-531.

U.S. Congress, Office of Technology Assessment (USOTA). 1993. Harmful non-indigenous species in the United States. OTA-F-565. Washington, DC: U.S. Government Printing Office.

U.S. Department of Agriculture (USDA). 2000. Guidelines for pathway-initiated pest risk assessments. USDA Animal and Plant Health Inspection Service (APHIS), Version 5.02. October.

U.S. Environmental Protection Agency (USEPA). 1989. Risk assessment guidance for Superfund. Volume II, Environmental Evaluation Manual. EPA/540/1-89/001. Washington, D.C.

U.S. Environmental Protection Agency (USEPA). 1997. Ecological risk assessment guidance for Superfund: Process for designing and conducting ecological risk assessments. EPA/540/R-97/006. Washington, DC: USEPA Office of Solid Waste and Emergency Response.

U.S. Environmental Protection Agency (USEPA). 1998. Guidelines for ecological risk assessment. EPA/630/R-95-002F. Washington, DC: Risk Assessment Forum.

With, K. A. 2004. Assessing the risk of invasive spread in fragmented landscapes. Risk Analysis 24, 803-815. 